\title{
Construction and evaluation of a Toolbox for the formulation of the Hydrologic component of the Basin Management Plans in Colombia
}

\author{
Victor H. Garzón ${ }^{1}$, Ricardo Garzón ${ }^{1}$, Pedro M. Avellaneda ${ }^{1}$, Erasmo A. Rodríguez ${ }^{1}$, and \\ Leonardo Alfonso ${ }^{2}$ \\ ${ }^{1}$ Department of Civil and Agricultural Engineering, Universidad Nacional de Colombia, Bogotá, Colombia \\ ${ }^{2}$ Hydroinformatics Chair, UNESCO - IHE, Delft, the Netherlands
}

Correspondence to: Victor H. Garzón (vhgarzonr@unal.edu.co)

Published: 17 October 2016

\begin{abstract}
The Colombian Ministry of Environment, Housing and Territorial Development issued the Policy for Integrated Water Resources Management in 2010, with the formulation of Basin Management Plans (POMCA) as a key component. The main purpose of these plans is to support land use planning and sustainable management of renewable natural resources. Since the announcement of the policy; however, advances in the formulation of POMCAs have been limited, due to the need of generating knowledge and the necessary information to formulate such plans. To contribute to the generation of such knowledge, we developed HidroCHEP: a Toolbox to support the formulation and hydrologic characterization of Colombian basins. In this paper, we report the design, architecture, implementation and use of the toolbox, to understand the climatic variability of the country and to improve predictions in ungauged basins. The use of the toolbox is illustrated and evaluated through its application in three pilot river basins (Pamplonita, Gualí and Ceibas) each with different level of available hydrologic and climatic data. This paper focuses on the use of the toolbox for the development of one of the products required by the technical guide for the formulation of POMCA, in the Pamplonita river basin. Main advantages and disadvantages of its application are evaluated. It is demonstrated that the toolbox has the potential to support the formulation of POMCAs in the country and to contribute to integrated national water resources management.
\end{abstract}

\section{Introduction}

Four of 214 large basins in the world (with more than $100000 \mathrm{~km}^{2}$ ) are located in Colombia, namely the Magdalena, Guaviare, Casanare and Meta rivers. The country has also three basins between 50000 and $100000 \mathrm{~km}^{2}$ in the Cauca, Inírida and Putumayo rivers, and over 700000 watersheds with areas smaller than $10 \mathrm{~km}^{2}$. The country's water network is complemented by the richness of groundwater and surface water storage, among lakes, ponds, reservoirs, marshes and swamps which reach 17000 water bodies (IDEAM, 2002). This water wealth represents for Colombia an asset that requires a good characterization for its proper management.
According to the National Water Study, ENA (IDEAM, 2010 ), over $80 \%$ of the municipalities are supplied by small water sources (e.g. streams or rivers with low regulation conditions and high vulnerability regarding droughts and water quality). These sources do not guarantee yearly water availability, so it is essential to understand the status and dynamics of these systems in order to organize and to make a proper sustainable resource management. According to projections made by the ENA, about the situation of scarcity and vulnerability for the period 2015-2025, Colombia would face serious difficulties to supply water to the population and other users in some regions "if we do not take important measures of conservation, planning and management of natural resources as well as pollution abatement" (IDEAM, 2010, $38 \mathrm{pp}$.). 
In March 2010, the Ministry of Environment, Housing and Territorial Development issued the Policy for Integrated Water Resources Management (PNGIRH), which presents recommendations for planning and management of water resources, including objectives, strategies, and indicators of implementation, monitoring and evaluation. A key component of the PNGIRH is the formulation of Basin Management Plans (POMCAs). The purpose of a POMCA is to evaluate and plan the management of natural resources at the basin level, maintaining a balance between socio economic use and the conservation of the physical and biotic components of the basin.

In this context, the environmental authorities are responsible to declare the planning state of a basin under their jurisdiction and to proceed with the formulation of POMCAs with partial or complete external technical support (National Decree 1729/2002, Article 19). According to the Colombian Institute of Hydrology, Meteorology and Environmental Studies (IDEAM), there are 39 basins and 343 sub-basins subject to management and eligible for POMCA formulation (IDEAM, 2004).

Colombia has the urgent need to generate knowledge and information to support the decision making, planning, management and sustainable use of water resources, which is also essential for water quality and hydro-ecological management (Sauquet et al., 2008), the productivity of stream and floodplain ecosystems (Harris et al., 2000). It is well known that numerous ecological processes in rivers are sensitive to their variations (e. g. Biggs and Close, 1989; Richter et al., 1996; Poff et al., 1997; Cattanéo, 2005; Beechie et al., 2006; Monk et al., 2006, 2007, 2008; Olden et al., 2006).

Data are significant to understand the complexities and the inter - relations of multiple physical and social aspects occurring in a river basin (Blöschl et al., 2013). Restrictions on the use and accessibility of basic information for hydrological purposes, added to the limited spatial and temporal coverage, are two challenges when modeling water resources in Colombian basins. In addition, the country needs more skilled professionals able to: apply and validate computational tools developed around the globe, understand the role of mathematical modeling to study physical processes, and evaluate different scenarios. The large climatic variability, in both temporal and spatial scales, has been a relevant challenge for the earth sciences in recent decades (Poveda, 2004), and this variability confuses the ability to understand the behaviour of water resources in the country.

It is evident the need to develop and consolidate technical supporting tools for professionals in the country, who are responsible for carrying out basin management. Proper understanding of these techniques, along with suitable computational tool, will allow manager to analyze different scenarios and support their decision-making process. To this end, the development of information systems that supports dynamically the decision making (IDEAM, 2010) is needed. This is the motivation for Universidad Nacional de Colombia, to construct a toolbox called HidroCHEP, which aims to covering different aspects from hydrological sciences, in order to support the diagnostic phase of the water component in any POMCA.

In this paper, we describe the design, architecture, implementation and use of HidroCHEP. Section 2 describes the design and construction of HidroCHEP, along with its use interface through a website. Section 3 presents the case studies implemented with emphasis on the Pamplonita pilot case study. Finally, in Sect. 4, a discussion and conclusions related to the use of HidroCHEP are presented.

\section{HidroCHEP: a toolbox for basin management plans}

The hydrological toolbox for the formulation of a POMCA, HidroCHEP, is an aggregate of computer applications, case studies and methodologies for formulating the hydrological component of POMCAs. As part of PNGIRH, the Ministry of Environment and Sustainable Development (MinAmbiente) published a technical guide for the formulation of POMCAs (MinAmbiente, 2014), which includes the description of six required stages: readiness, diagnosis, prospective and environmental zoning, formulation, implementation and monitoring, and evaluation. The characterization of the watershed is part of the diagnosis stage and has different topics and activities with defined products. The toolbox has a wide range of computer applications (most of them from free software), aimed to support the development of the products required by each topic presented in the technical guide.

HidroCHEP also includes a compilation of data sources for catchment characterization. It integrates tools and data sources with each POMCA required product, in order to complete the activity, facilitating the data collection, tools use and the development of the products.

The general architecture of HidroCHEP is indicated in Fig. 1, and it is based on adaptation and complementation of the architecture of similar existing hydrological toolboxes (e.g. eWater, 2012; CSDMS, 2008; Global Water Partnership, 2013). The toolbox is web-based, and three main sections are recognized, namely POMCA's guidelines, tools and case studies, described below.

\subsection{Guidelines for the construction of POMCA's topic-based products}

Each topic and activity related with the hydrological component of a POMCA has several required activities and associated products to each activity in order to understand the basin's water resources. The POMCA's topic section of the toolbox provides some guidelines to support the user in the construction of each product. The guide includes the description of the topic, its use for the construction of other products, the tools and necessary information, and a short explanation of the procedure to achieve the required products. 


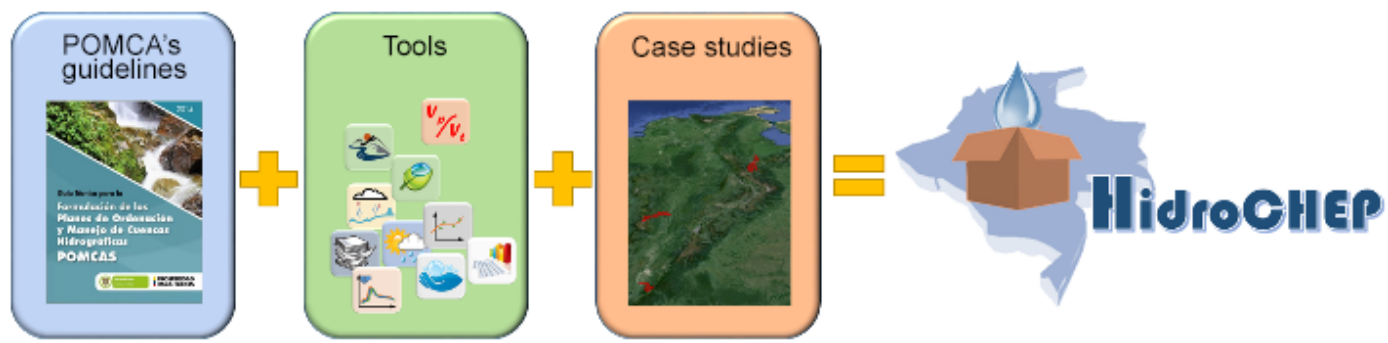

Figure 1. Main components of HidroCHEP's architecture.

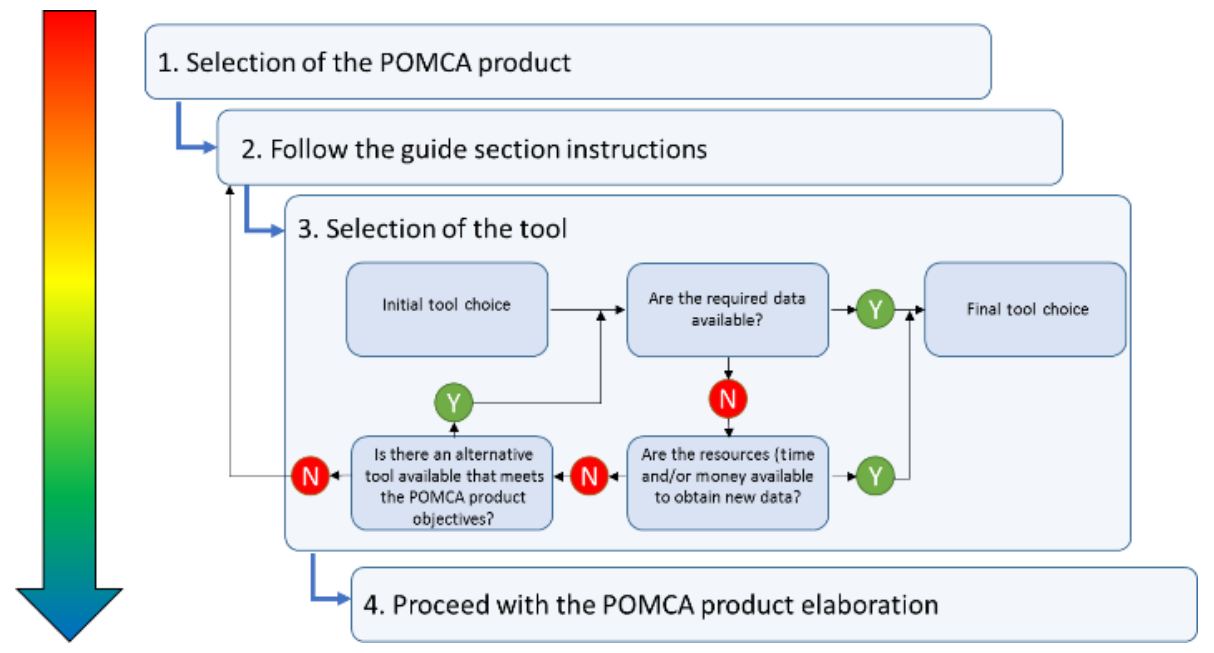

Figure 2. Flowchart of the use of HidroCHEP for the elaboration of a POMCA product.

Topics include hydrography, climate, hydrology, morphometry, and slopes. Each of these topics is divided into activities and each activity is briefly described. For instance, for the case of hydrography, two activities are recognized, namely (1) identification, description and river network drafting, and (2) characterization of drainage systems and patterns. Each activity is described following a structure that includes a description (where objectives, uses and products are mentioned), data needs, tools, and a step-based suggested procedure necessary to complete the activity.

\subsection{Hydrological tools repository}

One of the objectives of HidroCHEP is to collect different tools, essentially computer applications, which supports the construction of the products required by the POMCA. These are grouped into nine main categories: (1) data processing, tools to process and analyze the information typically used in hydrological applications according to the availability of the data in Colombia; (2) climate characterization, group of tools that allow the characterization of the meteorological variables required by the technical guide of the Ministry; (3) estimation of indexes, set of tools for the calculation of indices typically employed to characterize the hydrological behavior of a watershed; (4) water budget models, tools that allow to estimate water budgets in a watershed with different levels of aggregation and amount of information; (5) mathematical modeling: tools that supports the implementation of mathematical modeling for the simulation of the hydrological components of the watershed; (6) model's calibration and validation, tools used for calibration and validation of models within the framework of mathematical modeling in hydrology; (7) hydrography: set of tools that allow the characterization of the hydrographic network of a watershed; (8) water resources management, tools that include components of supply, demand, and water resources management, in order to evaluate different scenarios and hydrological responses; and (9) estimation of environmental flows, tools that allow to estimate environmental flows using different methods.

In addition, there is a category dedicated to the compilation of sources of information for obtaining the necessary meteorological and catchment characterization data, including that of global databases, as those produced by the national hydrometeorological network and national services.

\subsection{Case studies}

This section of HidroCHEP presents the case studies, showing the used tools for the development of the products re- 

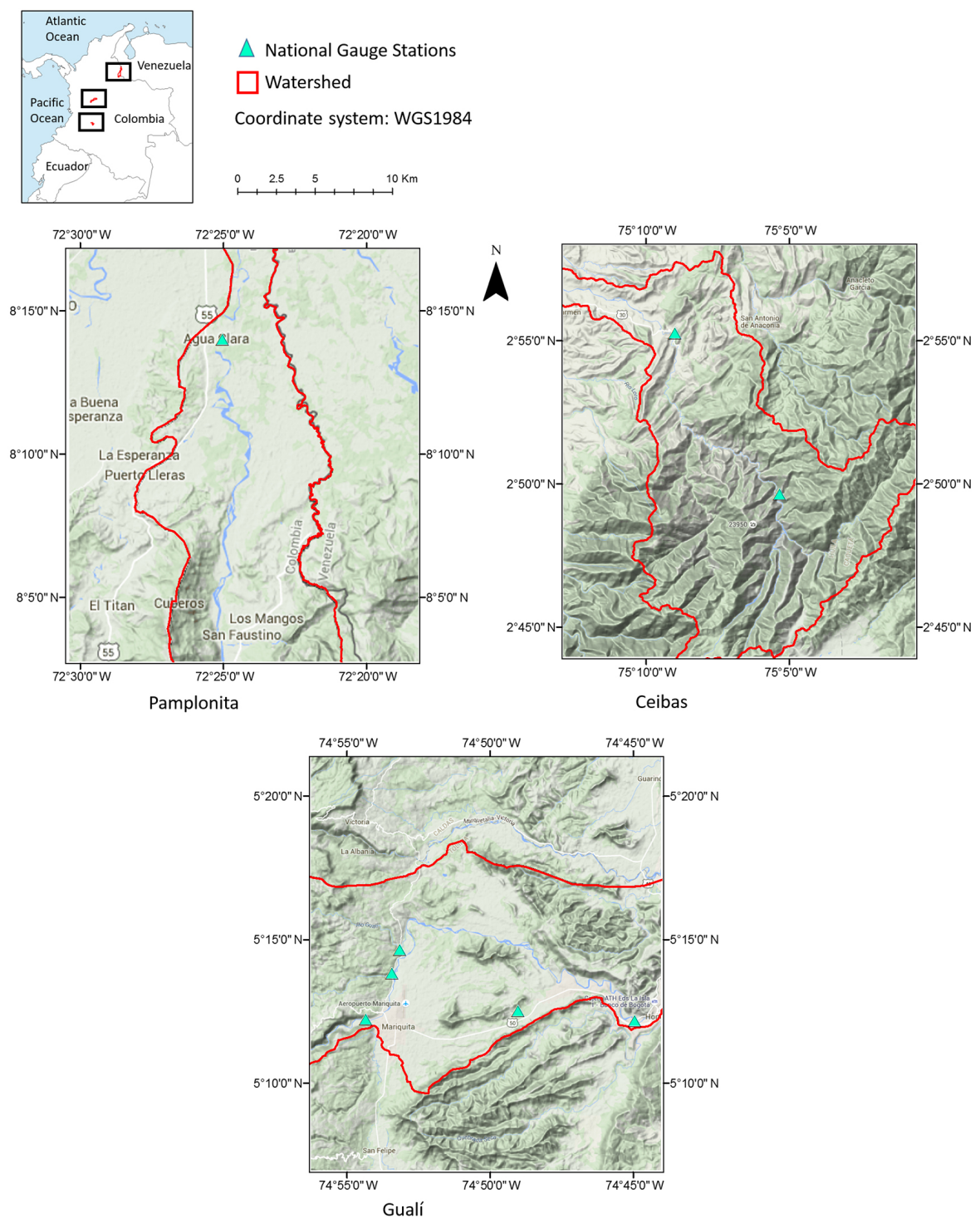

Figure 3. Location of the Pamplonita, Ceibas and Gualí catchments in Colombia.

quired by the technical guide, along with the results of the application.

Each case study follows a methodological framework as illustrated in Fig. 2. The user starts to consult the guide for the development of a specific product required by the technical guide, where several available tools are displayed. The user can make an initial selection of a tool, which is recommended for a minimal data information available; otherwise a different tool may be selected when there are more information.

\section{Application of HidroCHEP for selected case studies}

The actual version of HidroCHEP has three case studies of Colombian basins: Pamplonita, Gualí and Ceibas river basins. The locations of theses basins are shown in Fig. 3 . Each case has different levels of available monitoring and hydrometeorological information, thus illustrating the toolbox capabilities. This section presents, for the Pamplonita river basin, the use of the toolbox for the development of one of the products required by the technical guide.

The Pamplonita river basin is a transboundary basin between Colombia and Venezuela, characterized by low hydroclimatological instrumentation and the need to quantify their surface water resources. It is the main source of water supply for the city of Cúcuta (sixth most populous city in Colombia) and for rice crop irrigation. 


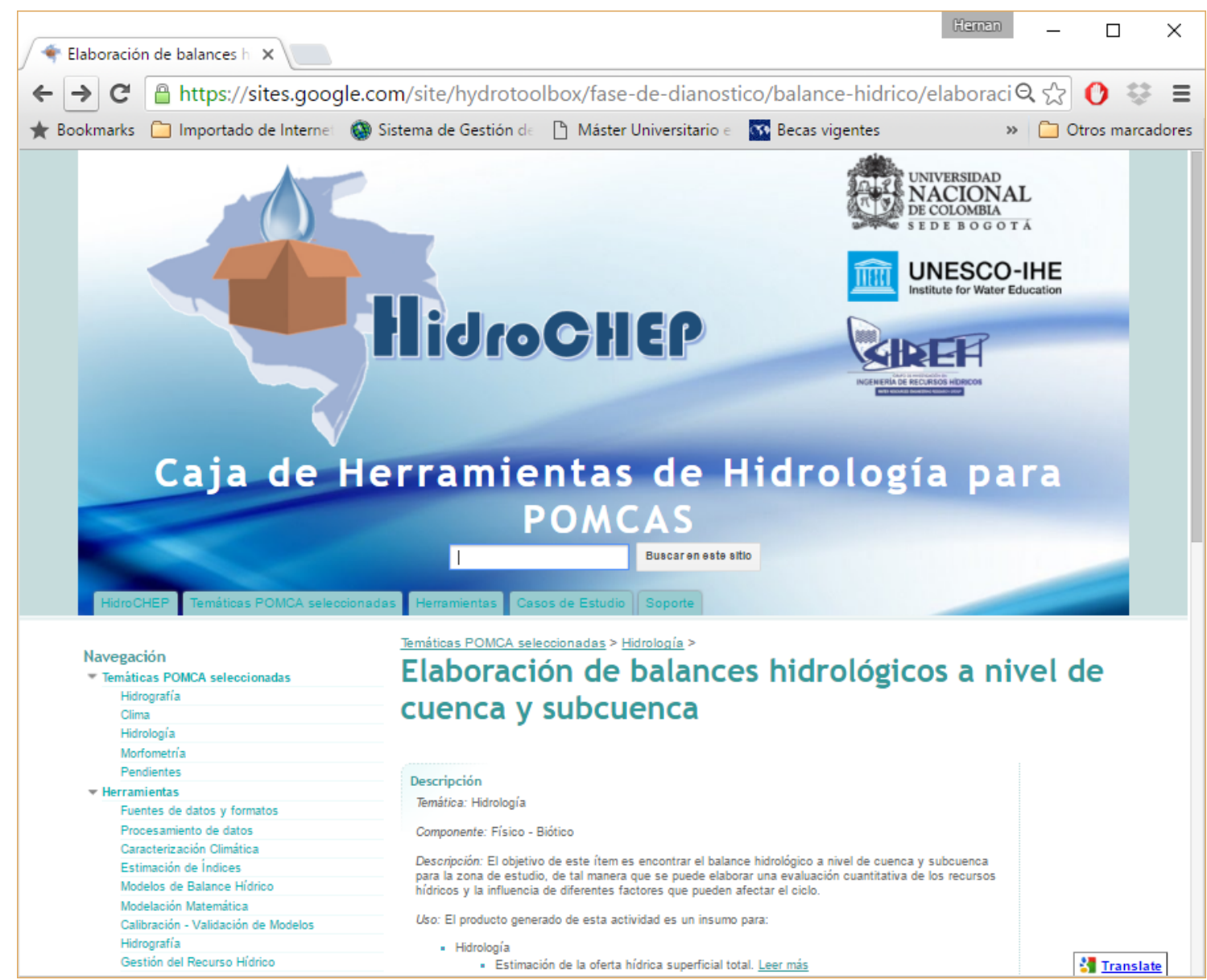

Figure 4. HidroCHEP interface showing a guide for a POMCA selected product.

\subsection{Selection of the POMCA's topic}

From the POMCA's topics included in HidroCHEP, it is possible to choose one out of five themes related to hydrological characterization: hydrography, climate, hydrology, morphometry and slope characterization. Each option has specific products. In the following section, the process to achieve product 06 "Making water budget at basin and sub-basin level", from the Hydrology topic (Fig. 4), is presented.

According to the guide shown in HidroCHEP, hydroclimatologic information of the study area is required. Hydrometeorological records are available for this basin (IDEAM, 2015).

\subsection{Selection of the tool}

One of the tools available to make a water budget in HydroCHEP is the software SAGA GIS (Conrad et al., 2015), a GIS with different interpolation options, and an administration and raster calculator. These features are adequate to meet the goals at this phase of the POMCA development (Fig. 5).
This software requires raster images of each variable considered for the water budget: a balance between rainfall and evapotranspiration.

\subsection{Making the POMCA's product}

As evapotranspiration data in the basin are not available, Turc's equation (Turc, 1961) is used to make an annual estimation, and Hargreaves's equation (Hargreaves and Samani, 1985 ) is used to make a monthly estimation. This is done using the raster calculator option of SAGA. The results are shown in Fig. 6.

Using the available information of precipitation and temperature, the monthly water budget from 1995 to 2014 is estimated. A raster calculator is programmed for several groups of images for each month, with the results shown in Fig. 6. Inter and intra annual variability of three of the main hydrological variables can be observed, which could help understanding the behavior of the Pamplonita river basin. 


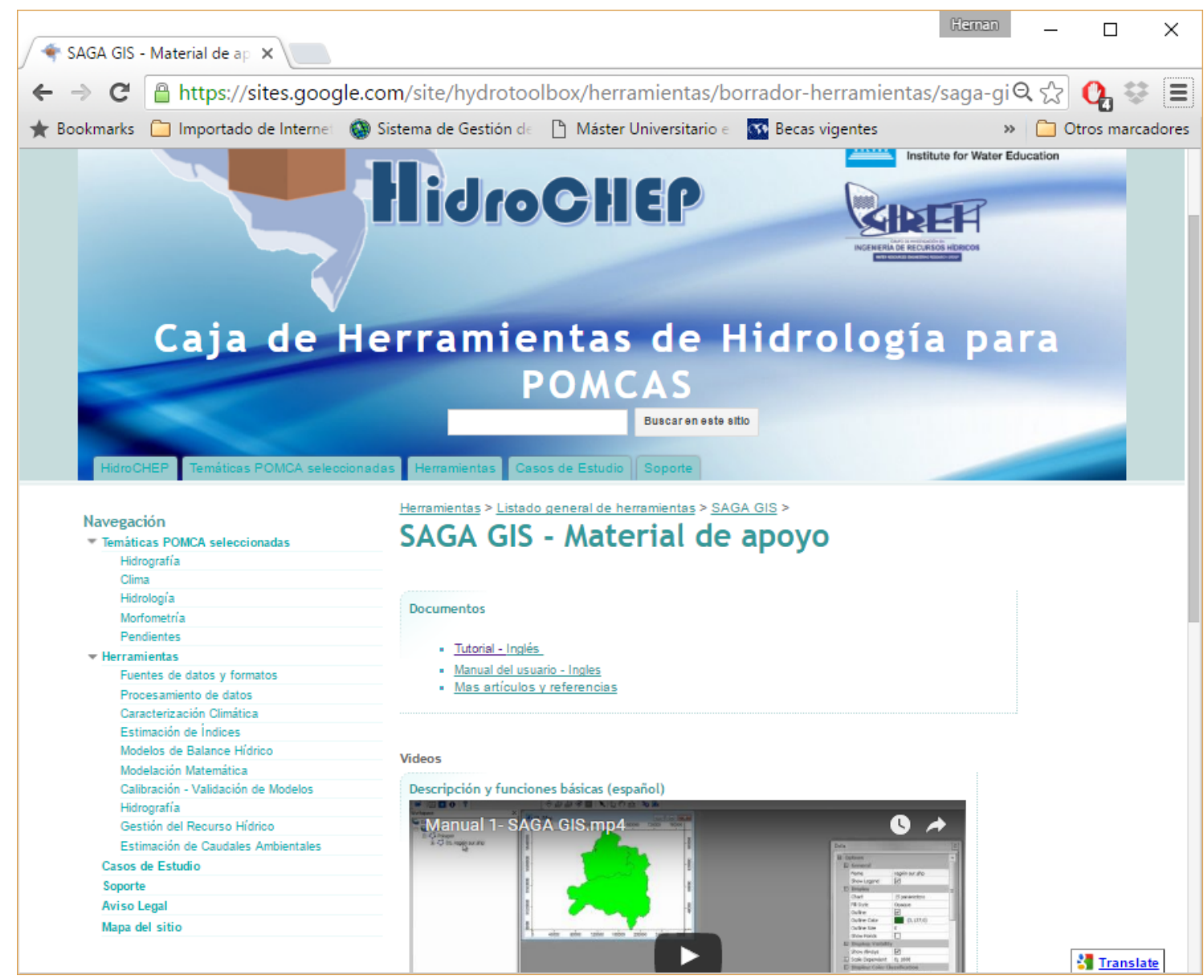

Figure 5. HidroCHEP interface showing the support material for the use of a tool.

\section{Discussion}

There are many tools and models globally available, which have been designed to achieve different hydrological purposes. Each model has different data requirements, and its implementation on real cases may not be straightforward for inexperienced novice user. Having large data sets does not necessarily mean that proper hydrological information is available (Gupta et al., 2008). As reported by Ackoff (1989) and Bellinger et al. (2004), it is necessary to understand that data conducts to information and do not represent the same. The latter embodies the understanding of a relationship of some sort, possibly cause and effect. In the same sense, information produces knowledge and, this one, in turn, understanding of the hydrological systems.

It is clear that, besides the need to have data available to understand the catchment behavior, techniques to exploit information from individual catchment studies are needed, which is required for the planning and management of water resources that is aimed by the PNGIRH in Colombia. In this context, HidroCHEP provides the linkage between data sources and tools, making its use efficient and helpful to understand the behavior of a basin.

Hence, one of the main contributions of HidroCHEP is to provide an easy access to different data sources including global and national hydrometeorological data, which allows the user to include not just traditional rainfall runoff data (and other hydrological data, e.g., soil moisture, evaporation, wind speed), but also other kinds of data related to the behavior of the catchment (e.g., vegetation, topography, drainage structure). The use of new data sources, such as satellite data, combined with field measurements and expert judgment of local hydrologist is also encouraged.

The interface of HidroCHEP enables the use and understanding of the tools that are provided, and at the same time it gives recommendations about their use in the formulation of POMCAs. The toolbox makes the information easy to be accessed by stakeholders, water professionals, and graduate and undergraduate students. Also, as the toolbox is composed mainly by free software, it facilitates the growth of a community of users and developers who can maintain and enhance its features. 

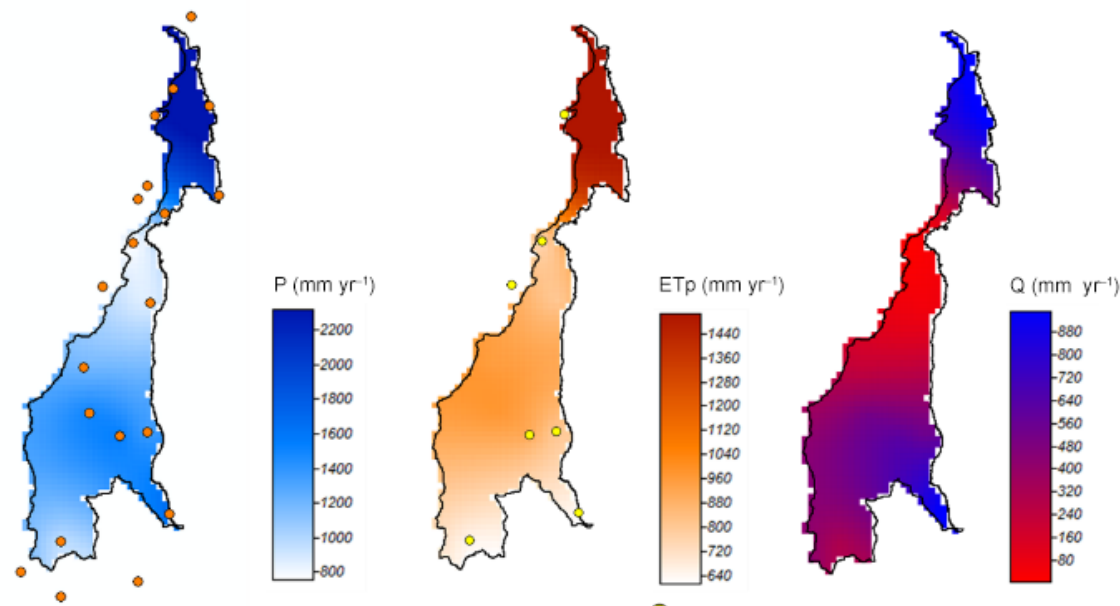

Rain gauges

O Temperature stations

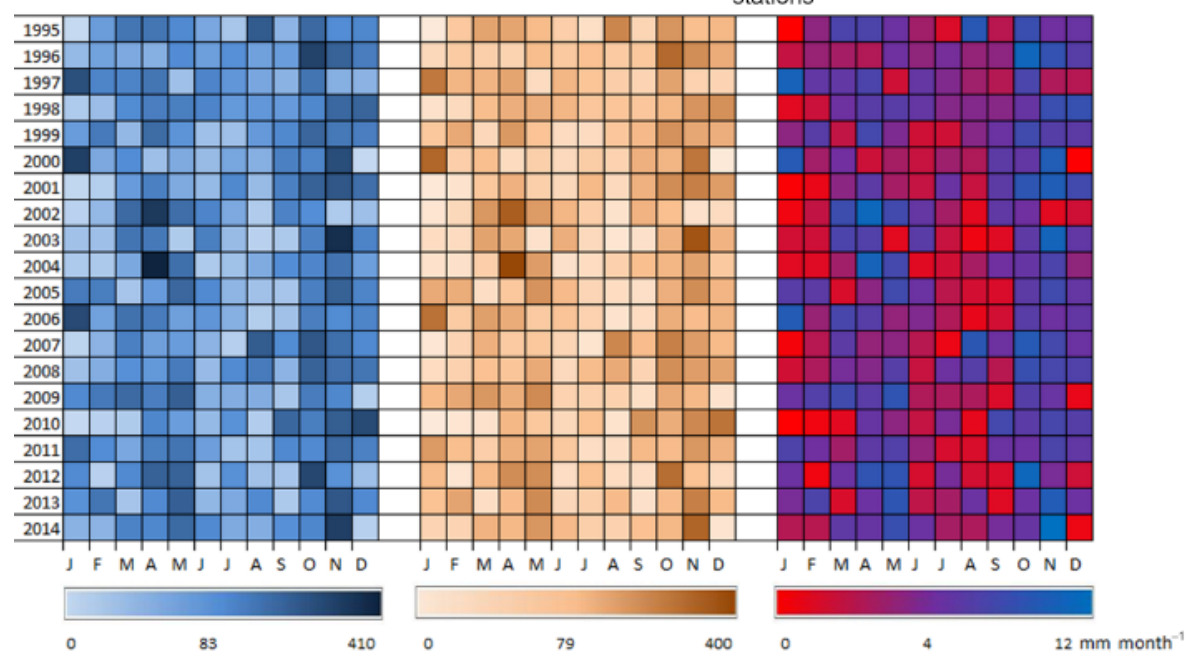

Figure 6. Annual and monthly water budget components for the Pamplonita's river basin using SAGA GIS.

With these contributions, it is expected that HidroCHEP provides a way to progress the formulation of POMCAS in the country and to advance the understanding of the national water resources. It is expected that stakeholders can gain confidence on their decisions, as they will be more informed for integral management.

HidroCHEP is under development. In this regard, a section dedicated to the users' feedback is foreseen, including a discussion forum, WIKIs, and the opportunity for scientist and professionals from the hydrologic sciences to share their own experiences.

\section{Toolbox availability}

All the elements of the Toolbox HidroCHEP can be accessed at the HidroCHEP website https://sites.google.com/ site/hydrotoolbox/. The tools, documentation and case studies are available on this website (in Spanish).
Acknowledgements. The toolbox described in this paper was developed at the Universidad Nacional de Colombia, with the support of UNESCO IHE, and the Colcuencas project (Piloting Colombia's New IWRM Policy in Key Catchments) under the programmatic cooperation between the Directorate-General for International Cooperation (DGIS) of the Dutch Ministry of Foreign Affairs and UNESCO-IHE, also called the DGIS UNESCO-IHE Programmatic Cooperation (DUPC1). Any opinions, findings and conclusions or recommendations expressed in this material are those of the authors and do not necessarily reflect the views of the Universidad Nacional de Colombia, UNESCO IHE, or the Dutch Ministry of Foreign Affairs.

\section{References}

Ackoff, R.: From data to wisdom, Journal of Applied System Analysis, 16, 3-9, 1989.

Beechie, T., Buhle, M., Ruckelshaus, M., Fullerton, A., and Holsinger, L.: Hydrologic regime and the conservation of 
salmon life history diversity, Biol. Conserv., 130, 560-572, doi:10.1016/j.biocon.2006.01.019, 2006.

Bellinger, G., Castro, D., and Mills, A.: Data, information, knowledge and wisdom, available at: http://www.systems-thinking.org/ dikw/dikw.htm (last access: April 2015), 2004.

Biggs, B. J. F. and Close, M. E.: Periphyton biomass dynamics in gravel bed rivers: the relative effects of flows and nutrients, Fresh. Biol., 22, 209-231, doi:10.1111/j.13652427.1989.tb01096.x, 1989.

Blöschl, G., Sivalapan, M., Wagener, T., Viglione, A., and Savenije, H.: Runoff prediction in Ungauged Basins: Synthesis across Processes, Places and Scales, Cambridge University Press, Cambridge, ISBN 978-1-107-02818-0, 2013.

Cattanéo, F.: Does hydrology constrain the structure of fish assemplages in French streams? Local scale analysis, Archiv für Hydrobiologie, 164, 345-365, doi:10.1127/0003-9136/2005/01640345, 2005.

Colombian Institute of Hydrology, Meteorology and Environmental Studies (IDEAM): Colombia's State Resources and Environmental Profile 2001, Bogotá - Colombia, 2002.

Colombian Institute of Hydrology, Meteorology and Environmental Studies (IDEAM): Zoning and coding watershed in Colombia, Bogotá - Colombia, 2004.

Colombian Institute of Hydrology, Meteorology and Environmental Studies (IDEAM): National Water Study ENA 2010, Bogotá Colombia, 2010.

Colombian Institute of Hydrology, Meteorology and Environmental Studies (IDEAM): Monthly hydrometeorological records: Selected years, 1995-2014, Retrieved from: National environmental information system, 2015.

Community Surface Dynamics Modeling System (CSDMS): CSDMS Model Repository, CSDMS Web Site, retrieved from: http: //csdms.colorado.edu/wiki/Model_download_portal (last access: April 2015), 2008.

Conrad, O., Bechtel, B., Bock, M., Dietrich, H., Fischer, E., Gerlitz, L., Wehberg, J., Wichmann, V., and Böhner, J.: System for Automated Geoscientific Analyses (SAGA) v. 2.1.4, Geosci. Model Dev., 8, 1991-2007, doi:10.5194/gmd-8-1991-2015, 2015.

eWater Cooperative Research Centre: eWater Toolkit, eWater web site, retrieved from: http://toolkit.ewater.org.au/ (last access: April 2015), 2015.

Global Water Partnership: Integrated Water Resources Management Toolbox (IWRM Toolbox), retrieved from: http://www.gwp.org/ en/ToolBox/ (last access: April 2015), 2013.

Gupta, H., Wagener, T., and Liu, Y.: Reconciling theory with observations: elements of a diagnostic approach to model evaluation, Hydrol. Process., 22, 3802-3813, doi:10.1002/hyp.6989, 2008.
Hargreaves, G. and Samani, Z.: Simplified coefficients for estimating monthly solar radiation in North America and Europe, Departmental paper, Dept. of Biol. And Irrig. Engrg, Utah State University, Logan, Utah, 1994.

Harris, N. M., Gurnell, D. M., Hannah, D. M., and Petts, G. E. : Classification of river regimes: a context for hydro-ecology, Hydrol. Process., 14, 2831-2848, 2000.

Ministry of Environment and Sustainable Development (MinAmbiente): Technical Guide for the formulation of Basin Management Plans (POMCAS), Bogotá - Colombia, 2014.

Monk, W., Wood, P., Hannah, D., Wilson, D., Extence, C., and Chadd, R.: Flow variability and macro invertebrate community response within riverine systems, River Res. Appl., 22, 595-615, doi:10.1002/rra.933, 2006.

Monk, W., Wood, P., Hannah, D., and Wilson, D.: Selection of river flow indices for the assessment of hydroecological change, River Res. Appl., 23, 113-122, doi:10.1002/rra.964, 2007.

Monk, W., Wood, P., Hannah, D., and Wilson, D.: Macro invertebrate community response to inter-annual and regional river flow regime dynamics, River Res. Appl., 24, 988-1001, doi:10.1002/rra.1120, 2008.

Olden, J., Poff, N., and Bledsoe, B.: Incorporating ecological knowledge into ecoinformatics: an example of modelling hierarchically structured aquatic communities with neutral networks, Ecological Informatics, 1, 33-42, doi:10.1016/j.ecoinf.2005.08.003, 2006.

Poff, N., Allan, J., Bain, M., Karr, J., Prestegaard, K., Richter, B., Sparks, R., and Stromberg, J.: The natural flow regime: a paradigm for river conservation and restoration, BioScience, 47, 769-784, doi:10.2307/1313099, 1997.

Poveda, G.: Hydroclimatology of Colombia: A synthesis from the Inter-Decadal scale up daytime scale, Revista Académica Colombiana, 28, 201-222, 2004.

Richter, B., Baumgarthner, J., Powell, J., and Braund, D.: A method for assessing hydrologic alteration within ecosystems, Conserv. Biol., 10, 1163-1174, doi:10.1046/j.15231739.1996.10041163.x, 1996.

Sauquet, E., Gottschalk, L., and Krasovskaia, I.: Estimating mean monthly runoff at ungauged locations: an application to France, Hydrol. Res., 39, 406, doi:10.2166/nh.2008.331, 2008.

Turc, L.: Evaluation de besoins en eau dírrigation, ET potentielle, Ann. Agron, 12, 13-49, 1961. 